\title{
Arquitetura da Santa Casa de Caraguatatuba/SP Architecture of Santa Casa de Caraguatatuba/SP
}

\author{
Maria Carolina Guilhem de Camargo' \\ 1 Universidade de Mogi das Cruzes - carol_guilhem@hotmail.com
}

Recebido em 17 de março de 2018; Aceito em 08 de junho de 2018.

\section{Resumo}

Esta pesquisa apresenta o edifício do Hospital Stella Maris de Caraguatatuba, inaugurado no dia 25 de Março de 1965 e sua arquitetura clássica da década de sua fundação. As relações existentes entre a arquitetura do hospital e a semiótica de Charles S. Peirce (1839-1914), mais particularmente, a sua classificação dos modos de raciocínio e as ideias de "ícone" e de "diagrama". A arquitetura, tem uma manifestação de linguagem não-verbal deve ser entendida não apenas como abrigo, tratando-se de um signo que provoca e desperta uma reação crítica no intérprete, seja ela negativa ou seja positiva.

Palavras-chave: Arquitetura, Semiótica, Hospital.

\section{Abstract}

This research presents the building of the Stella Maris Hospital of Caraguatatuba, inaugurated on March 25, 1965 and its classic architecture of the decade of its foundation. The relations between hospital architecture and the semiotics of Charles S. Peirce (1839-1914), more particularly, his classification of modes of reasoning and ideas of "icon" and "diagram." Architecture, which has a manifestation of non-verbal language, must be understood not only as a shelter, but a sign that provokes and arouses a critical reaction in the interpreter, whether negative or positive.

Key-words: Architecture, Semiotics, Hospital. 


\section{INTRODUÇÃO}

\section{UMA REFLEXÃO EM TORNO DA SEMIÓTICA E DA ARQUITETURA}

Para realizarmos uma avaliação mais profunda sobre a semiótica na arquitetura, devemos primeiramente entender o significado da palavra semiótica.

Em meados do século XVII, a palavra grega semeiotiké foi introduzida na filosofia por John Locke (16321704) filósofo inglês, como a designação para a doutrina dos signos em geral; doutrina postulada em seu Essay on Human Understanding, datado de 1690.

No início do século XX, o filósofo-lógico-matemático e norte americano Charles Sanders Peirce (18391914) retoma este termo com seu sentido original a partir da Lógica concebida como uma filosofia científica da linguagem, e dedicou toda a sua vida a fundamentar as teorias deste conceito, ou seja, a elaboração da Semiótica, a ciência dos signos. De acordo com a definição de Peirce, o conceito de semiose, a atividade do signo, é caracterizado como uma atividade eminentemente evolutiva. Os argumentos de seu pragmatismo, o postulado das relações lógicas existentes que se interrelacionam na entidade signo: os três elementos sígnicos: o representamen, o objeto e o interpretante.

Santaella (1992) analisa as questões lógicas implícitas nesse conceito peirceano, aprofunda as considerações de Peirce, e define o conceito de engendramento lógico, como a função primordial do complexo de relações que existe entre os três elementos da tricotomia sígnica.

De acordo com Brier (2003), a Semiótica começa com o processo de conhecimento, perguntando como a significação está ocorrendo em sistemas vivos e tornando possível a percepção e a cognição.

Já por outro lado, Greimas, russo (1917-1992); fundador da escola de Semiótica de Paris assume-se que o termo é empregado em múltiplos sentidos, ora como objeto, ora como teoria, ora como sistema, alterando-se de um para outro a relação englobante/englobado em relação à linguística.

A Semiótica de Peirce não é considerada um ramo do conhecimento aplicado, mas sim um saber abstrato e formal, generalizado. No âmbito da arquitetura filosófica de Peirce, a fenomenologia relaciona-se a categoria de primeiridade. A Fenomenologia trata das qualidades universais dos fenômenos em seu caráter fenomenal imediato, neles mesmo enquanto fenômenos.

Peirce associa às ciências normativas, que "descobrem leis que relacionam os fins aos sentimentos [...] à ação, no caso da ética, e ao pensamento, na lógica". (SANTAELLA, 2000). Já o papel da fenomenologia é proporcionar o fundamento de observação à lógica e à metafísica, posto que elas estão relacionadas à experiência com o que se exterioriza, ou seja, como o ser humano vai reagir diante do real, o que, por sua vez, se dá por meio da mediação de signos.

À percepção interessa tudo aquilo que está no aqui e agora, nos diz Peirce, mas "só percebemos aquilo que estamos equipados para interpretar". (SANTAELLA, 2000). A definição do termo "perceber" e todos os demais conceitos da obra de Peirce possuem uma ordem lógica e não podem ser tratados independentemente de outros conceitos. Perceber algo não requer apenas ver, mas estar diante de algo que se apresenta como um todo, que deve ser apreendido através de todos os sentidos, tanto do sensorial como do cognitivo.

A fenomenologia peirciana realiza a proeza de integrar o geral no particular, o concreto no abstrato, dentro de uma lógica ternária que não busca se livrar do fato bruto, de um lado, além de incluir o acaso, do 
outro. Em um dicionário da Língua Portuguesa encontramos uma definição de ARQUITETURA, do latim ARCHITECTURA, como:

1. Arte de criar espaços organizados e animados, por meio do agenciamento urbano e da edificação, para abrigar os diferentes tipos de atividades humanas. 2 . O conjunto de obras de arquitetura realizada em cada país ou continente, cada civilização, cada época, etc. 3. Disposição das partes ou elementos de um edifício ou espaço urbano. 4. Os princípios, as normas, os materiais e as técnicas utilizados para criar o espaço arquitetônico.

Fonte: arquitetura in Dicionário infopédia da Língua Portuguesa com Acordo Ortográfico. Porto: Porto Editora, 2003-2016. [consulta 2016-1128 21:15:00].

Na primeira definição, a palavra arquitetura está voltada à arte, organização de espaços, para abrigar diferentes tipos de atividades humanas; na terceira, a noção de disposição de partes, que associamos à ideia de organização contida na primeira; já na quarta definição, a de que essa arte se baseia em princípios, normas, materiais e técnicas. Assim, a arquitetura apresenta uma maneira própria de expressão e de representação, que é vivida e interpretada pelas pessoas diante das obras.

Como afirma Lankhorst (2013), para gerir a complexidade de uma grande organização ou sistema precisamos de uma arquitetura, ou seja, na conjugação de diversos componentes com o objetivo de formar um todo integrado que satisfaça um determinado fim.

\section{ARQUITETURA DO HOSPITAL STELLA MARIS EM CARAGUATATUBA: ALGUMAS REFLEXÕES}

O nome Stella Maris é uma homenagem em latim à Mãe de Deus, Maria, à verdadeira "Estrela do Mar". O hospital foi fundado no dia 25 de março de 1965 pela Madre Maria Teresa de Jesus Eucarístico, verdadeira alma apaixonada por Nossa Senhora, graças aos esforços das Irmãs do Sodalício Stella Maris e de seus colaboradores, contava naquela época com serviços de enfermagem para adultos e crianças, maternidade, sala de cirurgia consultório medico e bloco alimentar. Exatos três anos após abrir as portas, inaugura o novo pavilhão, um berçário com seis leitos.

Desta forma, consolidou-se no século XIX o sistema pavilhonar: grandes pavilhões de enfermarias, constituídos por pé direito generoso, ventilação cruzada e amplas janelas que possibilitavam a entrada de luz e sol. Na mesma época, na América do Norte, o modelo passou a ser substituído pelo partido arquitetônico de monobloco vertical: bloco compacto com vários pisos, que foi impulsionado pelo desenvolvimento acelerado da construção (TOLEDO, 2004). 


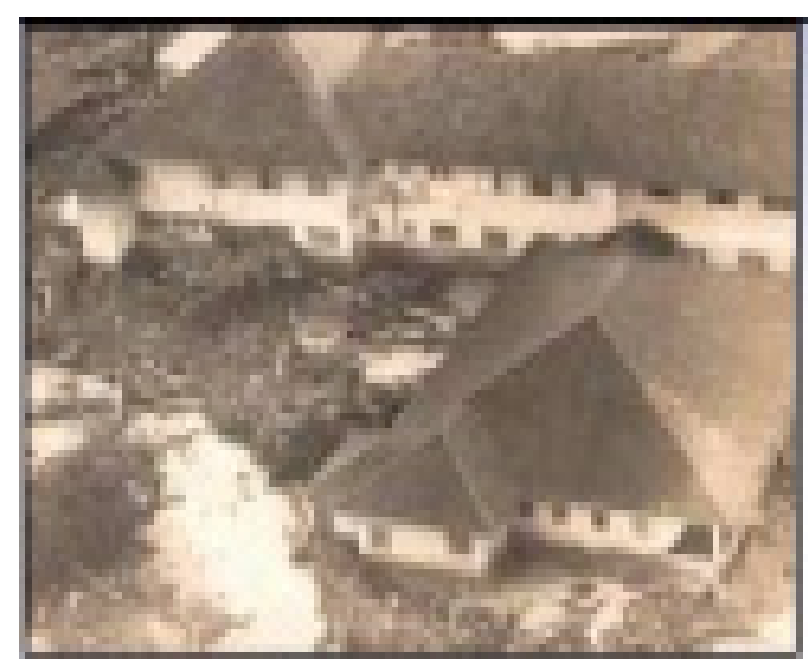

Figura 1: Hospital no ano 1967.

Fonte: Foto exposta no Hospital Stella Maris de Caraguatatuba em quadro.

Para Toledo (2004), com a adoção do monobloco vertical ocorreu uma certa ruptura entre a relação, até então parecia existir, entre práticas médico-hospitalares e o espaço arquitetônico, pois sua adoção coincidiu com o aumento de procedimentos tecnológicos no tratamento médico, colocando em segundo plano aspectos do ambiente e transformando o espaço em mero suporte físico das práticas curativas.

Após seis anos de abertura (1971), inaugurou-se a sala de entrada, sala de exames, sala de curativos, hall de entrada, sala de Raio X e câmara escura.

Voltando no tempo é interessante pontuar a tragédia que teve grande impacto na cidade e consequentemente para o hospital.

No dia 18 de março de 1967, a cidade localizada no Litoral Norte foi arrasada por um deslizamento da Serra do Mar. Número de mortos pode ter passado de 500. Era sábado, tarde da noite, 18 de março de 1967. O repórter Hamilton de Almeida foi enviado a Caraguá pelo mar. E eu, por terra, as estradas da Serra do Mar sepultadas. Após dois dias de chuvas constantes, a manhã daquele sábado ficaria marcada para sempre na história de Caraguatatuba, Litoral Norte de São Paulo, quando uma avalanche de pedras, árvores e lama desceu da Serra do Mar e destruiu a cidade. $O$ episódio, conhecido na época como hecatombe, provocou muitas mortes. Segundo as autoridades, teriam passado de 500, embora nunca tenha sido contabilizado um número oficial. A cidade ficou isolada e 3 mil dos 15 mil moradores perderam suas casas. Um balanço feito em 21 de março apontava que 30 mil árvores haviam descido as encostas e se espalhado pela cidade. O rio Santo Antônio, que corta a cidade, passou de 40 para 200 metros de largura. Para qualquer lado que se olhasse, a Serra do Mar apresentava deslizamentos como os que afetaram Angra dos Reis e llha Grande, no litoral sul do Rio de Janeiro, no ano passado.Fonte:http://www.taiadaweb.com.br/a-catastrofe-de-caraguatatuba-em-1967/; [consulta 2016-12-01 10:43:00]. 
Durante todos esses anos, mesmo com a catástrofe de 1967, as várias crises financeiras e as inúmeras dificuldades para continuar funcionando, o Hospital Stella Maris se matem ativo e firme e no propósito de atender aos mais necessitados.

Apesar das dificuldades financeiras enfrentadas, o Hospital Stella Maris tem investido fortemente na melhoria de sua infraestrutura e na formação de sua equipe técnica, utilizando recursos provenientes de verbas públicas, de captação de recurso através da Campanha da Nota Fiscal Paulista, e outros. O setor de Captação de Recursos do Hospital mantem também contato com políticos, ONGs, Governo Federal, Estadual, Municipal em busca de mais recursos e investimentos.

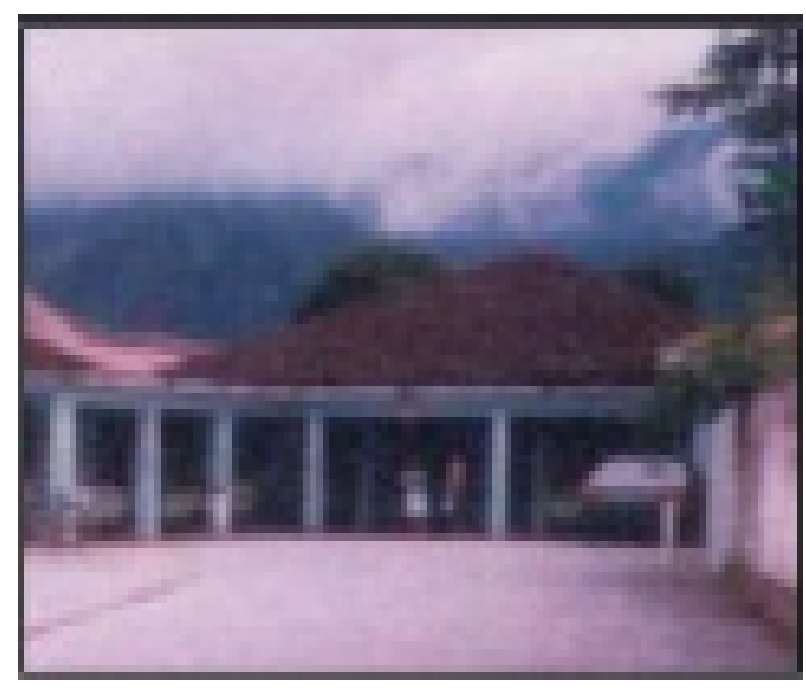

Figura 2: Hospital no ano 1992.

Fonte: Foto exposta no Hospital Stella Maris de Caraguatatuba em quadro.

Nos últimos seis anos inaugurou uma área anexa ao Pronto Socorro com 20 leitos de observação e emergência, foi ampliada a sala de emergência e reformada o Pronto Socorro, e também inaugurada a nova Maternidade e a Primeira UTI Neonatal do Litoral Norte Paulista.

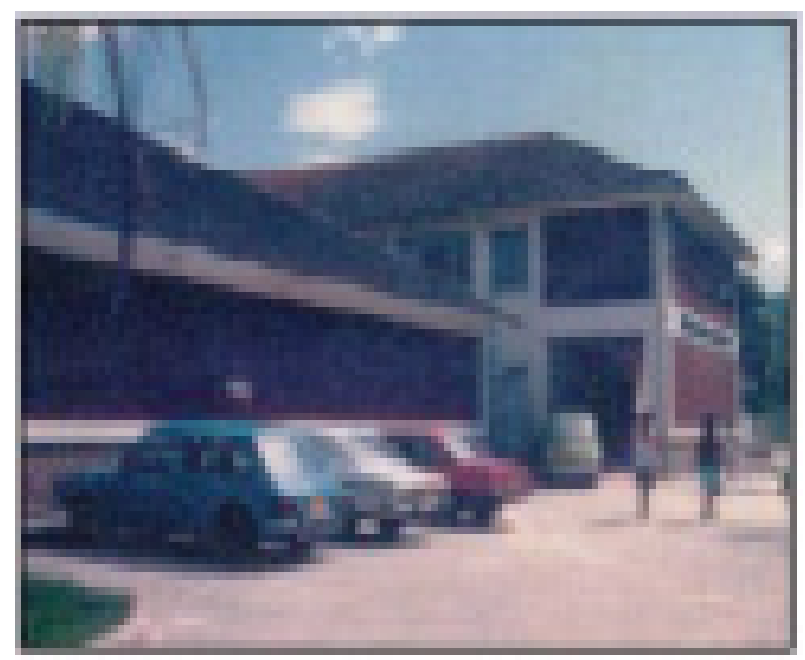

Figura 3: Hospital no ano 2002

Fonte: Foto exposta no Hospital Stella Maris de Caraguatatuba em quadro. 


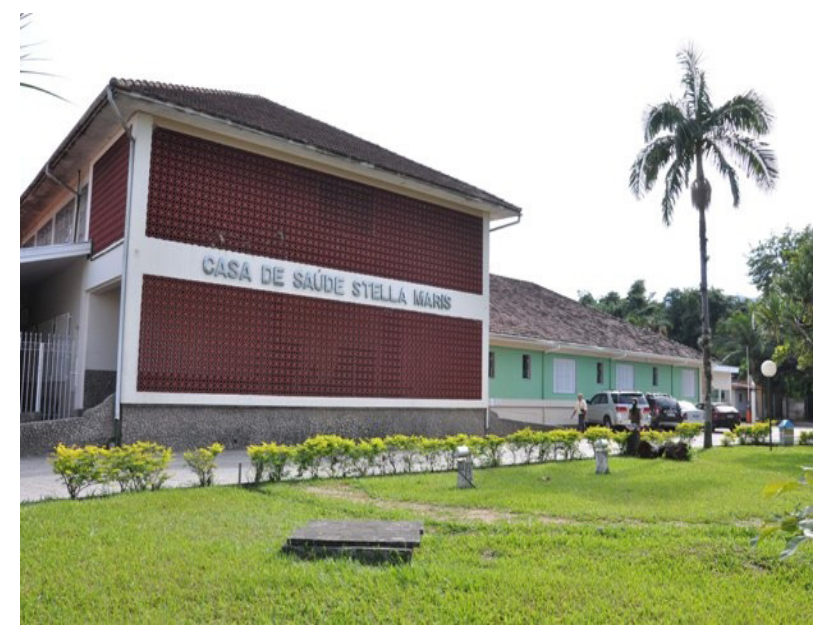

Figura 4: Hospital no ano 2016.

Fonte: http://migre.me/vG55U - [consulta 2016-11-02 08:52:30]

Na descrição deste tópico 3 e na observação das figuras de 1 a 4 pode-se observar que a arquitetura que aqui o hospital adotou busca uma maior humanização do usuário, pois a preocupação a princípio não parece ser otimização do espaço seja vertical ou horizontal, e sim por projetar espaços devidamente ventilados e com pé-direito alto, assim buscando melhor ambientação e conforto climático, como também essa amplitude vertical sem obstrução propiciando um contato com a infinitude do espaço.

Dessa forma, poderíamos dizer que a percepção desse usuário o remete a uma experiência sensorial, segundo Peirce, a primeiridade, aquilo que se pode obter do universo dos sentimentos, das sensações.

Pode se ousar a se referir a uma experiência extra-sensorial, pois a amplitude pode remeter ao espiritual, um lugar em que será cuidado no físico e no espírito.

Fica nos claro que a arquitetura em suas concepções de organização do espaço está diretamente relacionada com o produzir reações, e embora cada indivíduo possa traduzir de forma particular segundo o escopo de conhecimentos e experiências acumuladas, há um conjunto de fatores que podem produzir um determinado efeito no coletivo, confirmando a assertiva de Lankhorst.

A observação que se faz do tempo inicial da construção e as novas construções de ampliação pouco se mudou, no entanto, a verticalização já se caracteriza como preocupação da otimização do espaço e a percepção de amplitude perde a sua força.

\section{CONSIDERAÇÕES FINAIS}

Portanto quando pensamos em uma arquitetura, tentamos colocar significados nas obras haja vista que esta arquitetura queria se livrar do modernismo e seu estilo neutro, universal e onde não tinha espaço para os símbolos e seus significados logo pensamos em semiologia, ou seja, mostram que o significado e seus signos são importantes para o nosso dia a dia, pois trazem sentido e significado.

Uma arquitetura sem uma proposta, um significado que a justifica, será uma arquitetura sem personalidade. Vale lembra que também não é só um significado ou uma boa ideia que justifica um projeto, tem também a técnica proposta para a execução do programa. 
A arquitetura tem que ter um significado, sem se esquecer que cada pessoa que vê esta obra dará um outro significado mais pessoal.

\section{REFERÊNCIAS}

BASTOS, D.; FERNANDES, J.P. Fafe - História, Memória e Patrimônio. Fafe, Converso - editores e livreiros, 2013.

COSTEIRA, E. M. A. O hospital do futuro: uma nova abordagem para projetos de ambientes de saúde. In SANTOS, M.; BURSTYN, I (orgs.) Sáude e arquitetura - Caminhos para a humanização dos ambientes hospitalares. SENAS Rio, Rio de Janeiro 2004.

IBRI, I. Kósmos Noetos: A arquitetura metafísica de Charles S. Peirce. São Paulo: Perspectiva, 1992.

LANKHORST, M. . Enterprise Architecture at Work: Modelling, Communication and Analysis, 3rd Edition, Springer-Verlag. 2013.

TOLEDO, L. C. M. Do hospital terapêutico ao hospital tecnológico: encontros e desencontros na arquitetura hospitalar. In: SANTOS, M; BURSZTYN, I (Org.). Saúde e arquitetura: caminhos para a humanização dos ambientes hospitalares. Rio de Janeiro: Senac Rio, 2004.

PEIRCE, C. S.. Semiótica. 2a ed., São Paulo: Perspectiva, 1995

PEIRCE, C. S. Semiótica e filosofia. Trad. Octanny da Mota e L. Hegenberg. São Paulo: Cultrix, 1972.

SANTAELLA, L.. Peirce's Semioses and the Logic of Evolution. Signs of humanity l'homme et ses signens. Mouton de Gruyter, 1992.

. Difficulties and Strategies in Applying Peirce's Semiotics. Semiotica. Walter de Gruyter, n.97, p. 401-410, 1993. 8

. A teoria geral dos signos: Semiose e autogeração. São Paulo: Ática, 1995.

LINK: http://hospitalstellamaris.com.br/about-2/; [consulta 2016-11-28 21:36:00]

LINK:http://www.taiadaweb.com.br/a-catastrofe-de-caraguatatuba-em-1967/; [consulta 2016-12-01 10:43:00]. 